"I do it, but don't tell anyone! Personal Values, Personal and Social Norms: can social media play a role in changing pro-environmental behaviours?"

\title{
Niki Hynes
}

University of Curtin

\section{Juliette Wilson}

Department of Marketing, University of Strathclyde

\begin{abstract}
With increasing global pressures on agriculture as well as increasing environmental concerns, and confusing or even misleading information about food, consumers still need to make multiple daily decisions about food purchases and consumption. Consumers have complex personal and socially driven values as well as situational information affecting their food choices. This two-part study examines consumers' values and norms to determine how these relate to their personal food choices and the influence of social media based comparison tools on this behaviour.

Quantitative data was collected concerning personal values and norms as well as reactions to a social media comparison site. Our study shows that using appeals based on selfesteem and materialism and via social media would not be effective in bringing large-scale behavioural change towards environmentally friendly foods. Our contribution is twofold. First, we extend current knowledge around values, norms, beliefs and predicted behaviours within the context of environmentally friendly foods (EFF). Second, we examine whether these values or norms can be used as stimuli to encourage EFF purchasing through the use of social media. Whilst it is useful to understand these relationships, in order to exploit them and to effect change within society, social marketing messages would need to appeal to norms other than self esteem, materialism, rationality or peer influence through social media. Our study shows that as things stand now, social media is not an effective means of changing either values, norms or behaviours around EFF.
\end{abstract}

Key words: values, pro-environmental consumption, food, social media. 


\section{Introduction}

The latest IPCC Report on Global Warming representing input from 1,250 experts and 194 Governments gives warning that carbon emissions have soared in the last decade and are growing at double the previous rate (IPCC, 2014). Despite this ominous message the IPCC argue that rapid action can still limit global warming to an acceptable level. A key area where the need for change has been identified is in the production, trade and consumption of food products. Food production has also been identified as a critical contributor to numerous other environmental problems (Paul \& Rana, 2012; Tanner \& Kast, 2003). Fostering changes in the food chain is thus seen as a crucial step in the quest for sustainable development (Cheah \& Phau, 2011; Grankvist et al., 2007).

Although consumer's awareness of environmental concerns is high (Bleda \& Valente, 2009; Bonini \& Oppenheim, 2008; Dunlap, 2008; Vermier \& Verbeke, 2006), there remains a significant disconnect between consumer's stated environmental values and attitudes and their pro-environmental behaviours (Diaz-Rainey \& Tzavara 2012; Englis \& Phillips, 2013). Studies show that a far lower percentage of consumers actually buy environmentally-friendly products than those who say they are concerned about the environment (Thøgersen et al., 2012; Ubilava et al., 2010). Indeed, it seems only about $10 \%$ of consumers act on their proenvironmental attitudes (Englis \& Phillips, 2013). This disconnect between consumer attitudes and behaviours is even greater with food purchases for several reasons. First, food purchases tend to be low involvement and the result of quick decisions. Second, there is a lack of information about the environmental impact of food products, and third, consumers may hold different attitudes towards environmental issues dependent on specific food segments (Stanton \& Guion, 2010). 
Two models that have been extensively used to explain consumer's environmentally-friendly behaviour are the Theory of Planned Behaviour (TPB) (Ajzen, 1991) and the Norm Activation model (NAM) (Schwartz, 1977). Both models assume that consumers act in a rationally-informed manner, driven by self-interest.

The TPB predicts consumer behaviour based on the intention to perform the behaviour and levels of perceived behavioural control. It has been widely applied in relation to food purchasing / organic foods (e.g. Chen, 2007; Dean et al., 2008; Thogersen, 2007). The TPB assumes that two main external factors influence behavioural intentions; attitudes and subjective norms (Nilsson, von Borgstede, \& Biel, 2004). Subjective norms are derived from the way an individual perceives that other significant referrants (people or groups) would behave. The term "subjective norm" in TPB captures both social norms, and the individual's susceptibility to social pressure to perform in a certain way (Nilsson, von Borgstede, \& Biel, 2004). However, the TPB does not explicitly examine the relationship between personal and social norms.

The NAM (Schwartz, 1977) is wider in its explicatory power and also considers the role of personal norms as an influence on pro-social behaviours. Personal norms, as defined in the NAM, are experienced as a feeling of moral obligation to act in accordance with an individual's own value systems. The NAM proposes that personal norms are internalised from social norms, which describe acceptable or desirable ways of living. Personal norms then translate into behaviours when an individual is aware of the harmful consequences of their actions and ascribes responsibility to themselves to change the condition. There has been relatively limited application of the NAM to food purchasing behaviours (exceptions include Honkanen et al., 2006; Klöckner \& Ohms, 2009). 
There are two significant problems with using either of these models of consumer behaviour, with regard to environmental issues, and especially environmental/food issues. The first is that both models assume a rational relationship between norms, attitudes and decision-making, i.e. that the consumer actually considers the end result of their consumption decision and then acts in a rational manner. Yet for EFF, consumers often have limited information about the impacts of their decisions, and there is a need for quick decision.

The second problem is that there is still a lack of understanding of which particular values, norms and attitudes might impact the relationship between a stated intention and the actual behaviour. Most environmental research has focused on the relationship between attitudes and behaviours, but both behavioural models predict some sort of relationship between personal values and norms and social norms, and indeed, underlying personal values are seen as determinants of both attitudes and behaviours (Rokeach, 1973; Schultz \& Zelezny, 1999; Schwartz, 1992; Windrum et al., 2009). This complex relationship between consumer values and their attitudes is less well-documented (Rohan, 2000; Hauser et al., 2013). This is further complicated by numerous studies that use the terms norms and values in different ways.

In recent years, social media has shaped both social and personal norms and attitudes through the rapid and intense sharing of images and information. Social media's interconnectedness enables individuals to be quickly exposed to others' behaviours, and this exposure is likely to impact both personal norms and behaviours (Chu \& Kim, 2011; Zeng, Huang, \& Dou, 2009). In particular, for issues where social comparison is high, social media can significantly affect individual behaviours (Kropp, Laverack \& Silvera, 2005). However, the role of social media in influencing personal norms, values and attitudes has rarely been examined, and with respect to EFF, there appear to be no prior studies. 
The aim of this study is therefore twofold: to deepen our understanding of consumer actions towards EFF by investigating consumers' underlying personal values, and secondly, to determine the relationship between these deep-seated values and the impact of social media. In so doing, we hope to identify particular norms and values which are of significance in the decision to purchase EFF, and to understand how social media might be used to influence pro-environmental behaviours.

The first part of this study examines the values of individual self-esteem, social comparison level, materialism and contextual beliefs about the environment. These findings are then examined in the light of a social media setting (a mock facebook page) to determine if these deep-seated values could be used to affect the way in which they would share, compare and adjust their attitudes and behaviours. In so doing, this study extends previous work and introduces a mechanism for social comparison to determine if this could affect norms or behaviours.

The next section of this paper examines three key personal values that have been associated with consumer pro-environmental behaviour in previous research, as well as reviewing the Norm Activation model in more depth.

\section{Social and Personal Norms}

Social norms are ways of behaving that are agreed upon by society, with individuals expecting others to follow socially accepted expectations and obligations. Normative concerns appear to play a key role in pro-environmental behaviour by making people especially sensitive to how they think both themselves and others should behave (Thøgersen 1996). Lindenberg and Steg (2007) state that "a person in a normative goal frame takes the trouble to turn down the central heating when opening the window even if (s)he does not 
have to pay for the heating bill, simply because this is the "appropriate" thing to do" (Lindenberg \& Steg, 2007, p120).

The NAM proposes that social norms influence an individual's actual behaviours through their influence on personal norms (Figure 1) (Schwartz 1977). An individual's personal norms are defined as their own beliefs and are linked to their self-concept. This model is potentially useful in partially explaining prior research into the effect of social norms on pro-environmental behaviour (e.g. Cialdini, Reno \& Kallgren, 1990; 1991; Ebreo, Hershey \& Vining, 1999; Milfont, Sibley \& Duckitt, 2010).

Insert Figure 1 here

According to the NAM, there are two conditions that must be met for a personal norm to result in altruistic behaviours such as environmentally-friendly behaviour. First, is an awareness of consequences and, second, is the ascription of responsibility (Schwartz, 1977). In other words, an individual must understand both the result of performing (or not performing) an action, and must be willing to accept responsibility for that decision. This resultant feeling of obligation should then guide future behaviours. As discussed above, many consumers hold positive attitudes to the environment without behaving in an environmentally friendly way (Cleveland et al., 2012). Using the NAM, it would be argued that for an individual with a pro-environmental belief to purchase EFF, the individual must be aware of both the purpose of environmentally friendly consumption and the consequences of inaction, as well as accepting responsibility for purchasing EFF (Schwartz, 1977). In situations where individuals are initially unaware of their responsibilities, they could be influenced by either social norms (Hage et al., 2008), and/or cues (branding, labelling, signage etc.), which could make them aware of the consequences of certain actions. 
However, when the NAM has been applied to environmental behaviours, the results are, at best, mixed. Although some studies confirm the NAM (e.g. Milfont, Sibley \& Duckitt, 2010; Steg \& de Goot, 2010; DeYoung, 1986) other research contradicts this. In early environmental research in the 1970s, Heberlein and Black showed that personal norms could change consumers 'purchasing of lead free petrol. However, this finding was tempered with the fact that consumers choosing lead free petrol mostly thought that this would reduce their overall costs of petrol consumption (1981). In 1990, Vining and Ebreo studied the recent introduction of recycling, and also found that attitudes towards the environment were not significant in predicted recycling behaviours. In more recent research, there has been a separation of social norms into descriptive (what is) and injunctive (what ought to be) and it was found that social norms are only predictive of behaviour when the decision is focused on activating the norm (Kallgren, Reno, \& Cialdini, 2000).

The NAM also assumes that the gap between intentions and behaviours can be explained by the relative importance of each norm for an individual. In addition, this gap is also influenced by the level of disapproval an individual expresses when others transgress the norm, and the perceived obligation to follow the norm oneself. The more compelling these three factors, the more likely a social norm is to influence personal norms and behaviours (Lindenberg \& Steg, 2013).

Stern (2000) found strong support for the idea that personal moral norms form the basis for predicting pro-environmental actions, in terms of activist behaviour, although he did not study consumers' decisions. In the original NAM model, Schwartz (1973) proposed that acting in accordance with one's personal norms brings the individual a sense of self-esteem, whilst the opposite may evoke feelings of guilt. Kropp et al. (2003) examined values, selfesteem and susceptibility to interpersonal influence and found quite complex patterns of relationships between these variables and pro-environmental values with cultural and social 
norms having a complex relationship with personal values. Onwezen, Atonides and Bartels (2013) also showed that this feedback loop does not need to result from actions, but can occur through anticipatory judgements of emotions.

There remains however, a significant lack of research linking these values specifically towards EFF. The next section reviews three key values, which have been identified in prior research (self-esteem, social influence, and contextual values) and their relationship towards pro-environmental attitudes and EFF. We extend previous research by examining the role of materialism, which has been researched widely with other consumer behaviours, and strongly linked to the values of self-esteem and social comparison, but rarely researched with regard to pro-environmental behaviours or EFF.

\section{Self-esteem}

Self-esteem is commonly defined as an individual's positive or negative evaluation of themselves (see Rosenberg et al., 1995), or "the extent to which one prizes, values, approves, or likes oneself' (Blascovich \& Tomaka, 1991, p.115). Self-esteem is a complex value, (Rosenberg \& Pearlin,1978) and is inextricably lined to notions of social comparison. This relationship between social comparison and self-esteem has been studied widely (e.g. Aspinwall \& Taylor, 1993; Buunk et al., 1990; Wheeler \& Miyake, 1992), confirming the inter-relationship between these two variables.

Self-esteem is also closely related to how much worth consumers place on consumption i.e. the value of materialism. Thus, self esteem, social comparison and materialism are all variables which are highly influential in high involvement decisions, or in times of stress (Gibbons \& Buunk, 1999). In general, individuals with low self-esteem often show higher levels of materialism (Isaken \& Roper, 2008). Individuals with high levels of materialism may also be more likely to value the way in which their purchases contribute to 
their own self-esteem. In an EFF context, the more an individial values themselves, the more likely they are to put a high value on the food they consume, and might consider the extra money spent to be both something they "deserve" or something which reflects well on themselves. Therefore:

H1: There is a positive relationship between an individual's level of self-esteem and individual and social norms towards EFF.

\section{Social Comparison}

Social comparison is often used as a mechanism for consumers to understand themselves and their choices better (Festinger, 1954). Social comparison requires a sensitivity to social information indicating which behaviour adaptation is appropriate or desirable (i.e. social norms). Social comparisons are a central feature of consumer behaviour but the extent to which people compare differs markedly. Individuals who score highly for social comparison tend to be more focused on how they are perceived by others (Buunk \& Gibbons, 2007; Buunk \& Mussweiler, 2001; Festinger, 1954; Gibbons \& Buunk, 1999). Browne \& Kaldenburg (1997) found a complex relationship between self-monitoring (social comparison), and purchase intentions, arguing that reflections on identity can be influenced in different ways: the first being an overt relationship with self-monitoring or social comparison and the second being a more internal process. This supports the NAM model by suggesting social comparison impacts personal norms which then affect purchase intention, most likely through either an awareness of consequences and ascription of responsibility.

People are also heavily influenced by what they know about how others behave (Tarkiainen \& Sundqvist, 2005). Thus an individual's demand for organic products may be influenced by other's demand for the same products (Bekkers, 2007; Hughner et al, 2007). This has been shown to be influential in changing purchasing patterns of organic products 
and other environmentally conscious behaviours (Chen, 2007; Dean et al., 2008; Vermeir \& Verbeke, 2006; Tarkiainen \& Sandqvist, 2005). Given the extensive social attention to diet, animal welfare, climate change and health in the popular press, it is likely that individuals who undertake a high degree of social comparison are more likely to have positive attitudes towards EFF products. Therefore, it is likely that the more a person compares themselves to others, the more likely they are to be aware of, and sensitive to the issues around climate change and the environment:

H2: There is a positive relationship between an individual's level of social comparison and their individual and social norms towards EFF.

\section{Materialism}

Materialism can be described of as a cluster of related traits, attitudes, and values focussing on possessions (Belk, 1984; Kilbourne \& LaForge, 2010). Most research on materialism is based on Belk's (1984) research, which defines it as: "the importance a consumer attaches to worldly goods" (p291). Others describe it as the pursuit of happiness through acquisition rather than through other means, and suggest materialists judge their success largely by the number and quality of possessions (Richins \& Dawson, 1992). Materialism is an outwardly focused value, with materialists also evaluating both others and themselves by their consumption patterns (Rassuli \& Hollander, 1986), thus showing the inseparability of this construct from self-esteem and social comparison.

Highly materialistic behaviour usually results in increased purchasing of luxury products, stronger brand associations, and self-indulgence (Browne \& Kaldenberg, 1997). Indeed, most prior research on materialism has tended to focus on visible purchases or high involvement purchases (e.g. Browne \& Kaldenberg, 1997; Park et al., 2008). Very little research exists on the consumption of food, which is less overtly branded, consumed 
relatively quickly, and tends to be complex to demonstrate as a purchase. However, on the other side, materialists tend to be self-indulgent and link their success to both social comparison (being seen to eat certain foods, dine at certain restaurants, or shop in particular outlets) and their own self-esteem. This suggests that people with high levels of materialism might be likely to transfer this into an attitude towards EFF, therefore:

H3: There is a positive relationship between materialism and individual and social norms towards EFF.

\section{Contextual Values}

A final set of personal values or beliefs that are often considered as influential towards EFF consumption are contextual values. The contextual values identified in prior research consist of those concerning the environment in general (Englis \& Phillips, 2013; Tanner \& Kast, 2003). However, these values are complex and multi-dimensional in nature (Dunlap et al., 2000; Englis \& Phillips, 2013). Ebreo et al., (1999) argue that measuring attitudes towards the environment in general, rather than specifically towards environmentally-friendly foods, is a better predictor of the likelihood of environmentallyfriendly food consumption behaviours. Therefore:

H4: There is a positive relationship between pro-environmental values / beliefs and individual and social norms attitudes towards EFF.

\section{Social Media}

Whilst social comparison is not only an important determinant of underlying values, it is also an effective way of influencing an individuals' pro-environmental behaviours (Darby, 2006; Froehlich, 2009). Social media applications (apps) can be effective as a means of 
making small actions visible (Lähteenoja, 2008) or act as a form of persuasion (Froehlich et al., 2009). Social media apps have been used to stimulate sustainable behaviours of individuals in a number of ways, ranging from highlighting individual environmental impacts to incentivising group pro-social behaviours (Petkov et al, 2011). When social media is used to compare an individual's own actions to others, it becomes a form of social comparison (aka Festinger, 1954). This form of comparison has been shown to be particularly effective at influencing behaviour change, particularly when the behaviour is contextualised (Allcott, 2011; Goldstein et al., 2008; Jensen, 1986; Mankoff et al., 2010; Grevet \& Mankoff, 2009).

Presenting evidence through social media apps can help users to achieve more sustainable results by stimulating competition or collaboration (Grevet and Mankoff 2009; Van Leeuwen et al 2009). Their effectiveness can be facilitated in a number of ways. In many apps, the on-line social communities play a key role and the mobilisation of content generated by the key users is the main function (Langley \& den Broek, 2010).

In some applications, users can see the effect of their individual actions, for example by recording and learning about their energy consumption (Oakley et al., 2008). Other applications allow consumers to self-monitor their longer-term actions by offering temporal comparisons where individuals compare themselves in terms of their consumption behaviours over time (Albert, 1977). These can prove to be both effective and popular: in one social media based study of consumers' energy saving behaviours, consumers specifically asked for ways to compare their performance to their friends and peers (Mankoff et al., 2010). Comparison apps may use visual explanatory comparisons to enable consumers to perceive the consequences of their consumption behaviours, such as the number of trees needed to compensate for $\mathrm{CO}^{2}$ emissions (Holmes, 2007). Social media has been show to work effectively when contextualised; i.e. making very simplified behavioural changes such as re- 
using towels, turning thermostats down and so on (Goldstein et al., 2008). It may also give participants some form of recognition or validation for their activities, which can then be used to incentivise others probably through stimulating social comparison (Butler, 2001).

Social media could therefore present a unique and timely opportunity to encourage pro-environmental behaviours by using the impact of social comparison and personal values such as self-esteem to influence social and personal norms. However, very little, if any research, links the deep-seated personal values of social comparison and self-esteem with online comparative behaviours. It would seem logical that individuals with higher levels of social comparison are more likely to compare themselves to others, whilst those with higher self esteem are more likely to compare their actions against their own previous actions. Therefore:

H5: Individuals with higher levels of social comparison will be more likely to compare their EFF behaviours with others through social media.

H6: Individuals with higher levels of self-esteem will be more likely to compare their EFF behaviours with themselves through social media.

\section{Methodology}

In order to examine the relationship between values, norms and social media, a cross sectional quantitative study via an online survey was undertaken. This study was conducted with thre student cohorts from Strathclyde Business School in the UK. This convenience sample was chosen to include respondents who were most likely to be active in social media. The three groups included: final year Marketing students, Masters in Marketing Students and full time MBA students. A total of 353 students were contacted individually via email, and asked to participate in an online survey. The survey was run online using Qualtrics survey software, and reminders were sent out three times to all students. In total 172 participants 
responded, however, on checking for completion, only 107 were fully completed surveys, forming a final response rate of $30 \%$. Although all respondents were registered students, the profile of students ranged from part to full-time, with a significant percentage of older students in part-time or full-time employment, therefore giving a more representative sample than would be gained from only full time students. The problem of geographic bias (Winer, 1999) was mitigated through the MBA and Masters cohorts including students from 19 different countries.

The survey was pretested on a small number of students and other adults to test for readability and timing. All scales used in this study have been used in prior studies, although response formats were adapted to an even numbered Likert format forced-choice following other research in this area (Dickerson \& Gentry, 1983). The online survey had two separate sections: the first section included commonly used psychological scales. Respondents were first asked about their general thoughts on the environment derived from scales used by Englis and Phillips (2013), followed by questions on their self-esteem, attitudes towards others, personal norms and behaviours, and EFF products.

In order to examine the way in which social media might be utilised to change influence individuals norms around EFF and behavioural intentions, a mock facebook page was created, adapted from existing comparison facebook pages (such as those for fitness apps). The photo-shopped mock facebook page was then inserted in two instances into the Qualtrics survey. The first, was a single screen shot of the facebook page, with respondents asked to click on the part of the page they found most interesting. The second gave an expanded screenshot of the comparison graphs. These included three different comparisons: (1), their performance with their own previous performance; (2), their performance against a "friend's" performance; (3) their performance against "people like me". Respondents were 
asked which graph they would judge most important. Figures 1 and 2 show the fake Facebook page and the graphs for comparison.

The constructs were measured in the following ways:

Self-esteem was measured on the well-tested Rosenberg (1995) scale of ten items of which five were reversed as in the original scale. The scale factored into one item and had a high reliability.

Materialism was measured on the published MVS scale as used by Kilbourne \& LaForge (2010). This consists of three components including success, centrality and happiness. The scale showed high reliability on each of the three predicted subcomponents as well as a composite measure.

Social comparison was captured using the INCOM scale which has been extensively tested and looks broadly at how much individuals compare themselves with others in general rather than in a specific environment (Gibbons \& Buunk 1999).

Personal norms towards EFF and social norms towards EFF were measured using scales adapted from those by Tanner and Kast (2003).

Contextual values/ beliefs used the multidimensional construct developed by Englis \& Phillips (2013) from the NEP scale (Dunlap et al., 2000) to measure consumers' attitudes towards environmental issues. This predicted three component variables reflecting different groupings of items. First 'Nature Rules', which relates to beliefs that humans should not abuse the environment and that there are negative consequences of doing so. Second, 'Humans Rule', which counters with a belief that humans are meant to rule over nature and can counteract any negative consequences they have on the environment. Third, 'Growth Limits', the belief that there are limits to the amount of growth the environment can support. 
In this study only the first two components were identified through CFA, and 'Growth Limits' showed neither validity nor reliability. The relationship with Nature Rules is therefore expected to be positive with norms towards EFF, whilst the contradictory Humans Rule scale is expected to have a negative relationship with norms towards EFF.

Descriptive summaries of all scales and their reliability are reported in Table 1 and details of the scale items are given in Appendix 1.

\section{INSERT FIGURES 2 AND 3 HERE}

\section{Results}

The age range of respondents was between 20 and 50 years of age, with an average age of 27 years. Forty four percent of respondents were male and $56 \%$ female. The means, ranges and reliabilities for the scales are presented in Table 2. All reliabilities for scales except "perceived barriers" and NatureRules were above the value of 0.7 (Nunally, 1978) but these two met the second criteria of 0.6 (Nunally, 1978).

\section{INSERT TABLE 1 HERE}

In order to examine the relationships between the personal values of self-esteem, social comparison, materialism and contextual values towards the environment, linear regression and moderated regression models were used with two dependent variables: Individual attitude towards EFF and social norms towards EFF. The results of the multiple regression models are shown in Table 2.

INSERT TABLE 2 HERE

H1 examined the effect of self-esteem on individual and social norms towards EFF. 
Table 2 shows that neither model (individual norms or social norms as dependent variable) showed a significant relationship and so $\mathrm{H} 1$ is not supported, i.e. this study found no direct relationship between self-esteem and EFF norms. H2 predicted a positive relationship between social comparison and individual and social norms towards EFF. H2 was partially supported with a non-significant relationship between social comparison and individual norms, but a positive and significant effect on social norms. This suggests that individuals who strongly compare themselves with others also make stronger judgements about whether others should act in an environmentally-friendly manner, but appear not to apply these to their own personal norms.

H3 predicted a significant positive effect between materialism and individual EFF: that is the more materialistic a person is, the more likely they are to value the types of products, or foods that they purchase, as reflections of their own importance. However, this relationship was significant but negative, suggesting a higher level of materialism leads to stronger negative individual norms about EFF. No relationship was found between materialism and social norms for EFF. That is, materialism affects personal norms, but appears not to have a relationship with social norms.

Contextual values (Nature Rules) had a positive and significant relationship for both individual and social norms and therefore H4 was supported. This finding supports most previous research that consumers with pro-environmental values/ beliefs also transfer this to attitudes towards food (Aertsens et al., 2011; Cheah \& Phau, 2011; Hauser et al., 2013; Tanner \& Kast, 2003). The stronger an individual's views of contextual norms, the more likely they are to think that both they and others should change their behaviours.

Because the values of self-esteem, materialism and social comparison are closely interlinked, it seemed likely that these values are more likely to act in a combined way to 
affect EFF. Moderated regression was conducted using interaction terms (social comparison by self-esteem, social comparison by materialism, social comparison by Nature Rules and social comparison by Humans Rule). Prior to moderated regression, all variables were meancentered (Hayes, 2008). In order to examine the moderation relationships, the change in $\mathrm{R}^{2}$ was measured in the models with and without the moderating variables. Models were examined for multi-collinearity and showed no such issue.

\section{INSERT TABLE 3 HERE}

As can be seen in Table 3, there is a significant interaction effect between the independent variables: the change in $\mathrm{R}^{2}$ was largest with the model with interaction terms and individual norms. The $\mathrm{R}^{2}$ changed from .173 to .308 and the adjusted $\mathrm{R}^{2}$ was also raised from .134 to .243 . Hence the relationship between self-esteem, social comparison and materialism and individual norms appears to be complex and a product of all 3 values acting together.

For social norms, the overall model also showed a very small increase in adjusted $\mathrm{R}^{2}$. The direction of the effects did not change and remained similar, and significant effects were seen with social comparison as a moderating variable. For decision-making models, an $\mathrm{R}^{2}$ of this magnitude is reasonably high since many factors affect behaviour, and are not included in each model.

Having found that contextual norms, social comparison and materialism impact norms towards EFF, the second stage of the model examined how individuals would prefer to compare their EFF behaviours to others or themselves. To examine this relationship, respondents were grouped into 2 categories: those that prefer to compare their EFF behaviours to themselves, and those that prefer to compare themselves to others (either peer group or friends). Binary logistic regression was run to look for significant indicators of this 
form of behaviour including all independent variables previously tested. In addition, age and gender were included. Of these variables, only Social comparison and Nature Rules/ contextual values (not hypothesised) were significantly predictors of group membership, with $89 \%$ of "comparison with oneself" responders being correctly identified. This suggests individuals that hold strong contextual values and have low levels of social comparison are more likely to self-monitor, i.e. to prefer to measure their EFF behaviours based on prior personal performance.

It seems that the picture for identifying which individuals prefer social comparison is more complex, with the variables in this study only accounting for as little as $43 \%$ of group membership. It seems likely that other personal factors play a much stronger role in whether consumers wish to compare their EFF behaviours with others, and this certainly warrants further research. This finding is significantly different from previous research concerning other comparative activities, such as fitness, health etc. and further research is required to understand why pro-environmental activities appear to be decoupled from social comparative activities.

\section{INSERT TABLE 4 ABOUT HERE}

\section{Discussion}

The aim of this study was twofold: first, to deepen our understanding of consumer norms towards EFF by investigating consumers' underlying personal values. Second, to determine the relationship between these deep seated values and how social media might be used to change their pro-environmental behaviours. The first part of this study examined the values of self-esteem, social comparison, materialism and contextual values about the 
environment.

Social comparison is shown to have a complex effect on personal norms. It appears to have a direct effect on social norms related to EFF consumption i.e. individual's opinions on how other people should act, but did not show a direct effect on personal norms. Instead, social comparison appears to moderate or interact with the relationships between self-esteem, materialism, contextual values and individual norms. This suggests that whilst self-esteem has no direct impact on individual pro-EFF norms, if individuals start to compare themselves with others, then self-esteem and social comparison act together to encourage pro-EFF norms. This finding extends and gives more depth to the NAM, which suggests a direct and linear relationship between social and personal norms. Our study suggests that underlying personal values also impact both directly and indirectly to these variables.

This finding suggests that by linking both personal and social norms, consumers could be encouraged to increase EFF behaviours, but that influencing either set of norms alone is insufficient to change behaviours.

From a managerial point of view, the use of "self worth" is becoming more and more popular in advertising campaigns, and has led to new research, which examines the interrelationships between consumer decisions and deservingness (Cavanugh, 2014). Famous marketing campaigns have focused in on particular norms: for example, the widespread success of L'Oreal's "because you are worth it" campaign for beauty products appeals directly to an individual's values of self esteem and materialism. However, whilst these appeals are successful in advertising campaigns for "indulgent" products such as luxury goods and high calorie foods (Cavanaugh, 2014) this study suggests that this strategy would not easily transfer into pro-environmental food choices.

Interestingly, research has shown that the "because you are worth it" campaign may not actually tap into the more obvious values of self esteem and materialism along, but may 
actually be highly effective only because women compare themselves directly to other women (Stuart \& Donaghue, 2012). This confirms the complex nature of the relationship between the personal values self-esteem, materialism and social comparison, and suggests that any future social marketing campaigns need to address all three values.

The picture is slightly more complex with individuals who already have proenvironmental contextual values: the link between these and EFF values is negatively moderated by social comparison. This seems to suggest that individuals who believe they should behave in environmentally friendly ways do so because they hold strong generalised beliefs about the importance of the environment. However, this belief is then decreased when they consider others. This is an interesting dilemma, and one which needs further investigation: whilst individuals might wish to act in pro environmentally-friendly ways, the more they consider other's actions, the less likely they are to act on their own values. This could reflect a degree of fatalism: "its not worth me making the effort, if everyone else does not" (Lorenzoni et al., 2007). Within the context of the NAM, this finding suggests that even when social and individual norms would lead to pro-environmental actions, consumers may behave differently by ascribing responsibility to "others" rather than themselves.

Materialism has a direct negative effect on attitudes towards EFF consumption: Highly materialist individuals are less likely to purchase EFF products, and when the interaction effect of social comparison is introduced, this negative relationship is strengthened. Richins (1994) found that more materialistic individuals tended to value items that are consumed publicly and possess public meaning, rather than personal or subjective meaning. This negative relationship could be explained by the lack of public display possible with food choices (it is difficult to publicly display pro-environmental food choices, even if this choice were to be considered to define or illustrate success). 
In contrast, individuals who are low in materialism appear to be more interested in EFF products, reinforcing the view that for them, certain objects and possessions are used to express private meanings, rather than for public display (Browne \& Kaldenberg, 1997). Again, this finding appears to contrast the relationship between deservedness and materialism that is seen in other products (Cavanaugh, 2014). This suggests that for social marketing campaigns to encourage EFF foods, social norms and values about materialism only being important when it can be outwardly portrayed need to be broken: perhaps by introducing the idea that EFF not only make "you feel good" but also "does good".

Interestingly given these values, the second stage of the study, investigating the role of a comparison facebook page, gave considerably different results. Whilst it would be expected that consumers with strong contextual (environmental) values would like to compare their environmental progress with either their past performance or others, this was only evident for comparison with their own activity. This suggests that unlike fitness or energy usage comparisons, consumers are unlikely to be motivated by comparisons with others concerning their EFF behaviours. Although individuals with high values of social comparison do indeed consider how others act and are more susceptible to comparative messages, this is only a weak relationship when applied to foods. Again, this raises the issue of why foods would be different to fitness, health or beauty products where social comparisons are used with great effect to impact individual behaviours. For example, fitness apps use feedback on personal performance as the $3^{\text {rd }}$ most important effect on personal behaviour change (Conroy et al, 2014). The complex relationship between sharing information on public sites, comparison information to change behaviours and the specificity of food consumption suggests that simple comparison sites such as used for fitness and energy use are currently inappropriate for food, but that further research is required. 


\section{Conclusions}

Within this study we have made an exploratory investigation into personal values and norms around pro-environmental food consumption. Our contribution is twofold. First, we extend current knowledge around values, norms, beliefs and predicted behaviours within the context of EFF, by examining the inter-relationships between personal values (self esteem, materialism and social comparison) and personal and social norms. Second, we examine whether these values or norms can be used as stimuli to encourage EFF purchasing through the use of social media. Whilst it is useful to understand these relationships, in order to exploit them and to effect change within society, it is important to know which media or social marketing methods would work.

It appears very strongly from our data, that using appeals based on self-esteem and materialism via social media would not be effective in promoting large-scale awareness of EFF. Given the extensive current use of "deservingness" in current advertising campaigns and the extensive use of social comparison through social media, this seems to imply that consumers do not consider environment, or perhaps food, to be sufficiently important to themselves to need to socially compare their behaviours. Indeed, the social norms around food purchasing may be loose, and ill-defined leading to ambiguity about "what is the right thing to do?" This could be a result of weak or conflicting media messages about good behaviours, and limited information about which products would be environmentally friendly. Indeed, consumers are inundated with messages around food purchases and consumption ranging from health concerns, to environmental concerns.

Given the negative relationship between materialism and EFF, there would initially seem to be room for social marketing campaigns to confirm the indulgent side of EFF. If health messages focus on self-indulgence rather than the environment, then consumers with higher materialistic values might be persuaded to value, and therefore purchase EFF. 
However, the initial social media comparisons suggest a more complex relationship. Likewise, given the interaction effect of social comparison, materialism and contextual values, there may be scope for social marketing campaigns to emphasise that other people are more likely to indulge themselves with EFF.

Whilst the findings show a positive relationship between those with proenvironmental values and attitudes towards EFF products specifically), this is not found with respect to the specific responsibilities of humans towards the environment. This partially supports other studies that show contradictory findings (Vega-Zamora et al., 2014).

The lack of societal knowledge and indeed trustworthy information about what constitutes EFF complicates the matter further. Vega-Zamora et al., (2014) argue that "organic" is a heuristic cue that enables people to infer that these products possess an extra degree of quality, health or authenticity. In contrast, there is currently no single label or social marketing message that is used to explain? whether a food is environmentally friendly.

Overall, these findings suggest that the current rational models of consumer behaviour such as the TPB and the NAM are insufficient to capture complex, value ridden decisions. Greater interdisciplinary knowledge is required which bridges the psychology/marketing literature with that concerned with foods and the environment.

Finally, there are of course some limitations in our study, including sample size and type. Future research should examine a wider range of people to determine if these relationships exist across different life stages. Further, qualitative research could be used to better understand the complex relationship between social comparison and core individual values and the idea that it is acceptable that " $P$ " and "others" behave in certain ways at different times. In addition, the mock Facebook page was limited in scope, as was the ability to determine if people were likely to use or not use such a page. The effect of social comparison and materialism may be different at different levels of these values and could 
even be non-linear: Verplanken and Holland (2002) showed that only when values are cognitively activated and are central to the self, will they impact other values.

Finally, it is worth conducting more research on the core finding of this study: that is the negative moderating effect of social comparison on contextual values: the "if others don't care, why should I' type of feeling that appears to be significant and influential. Whilst social media comparison sites and apps would perhaps go someway towards dealing with this issue, the feelings of privacy around food purchasing may be too strong to allow comparisons. Again, in this exploratory study it would seem that both the NAM and the TPB are insufficient to explain this complexity. It appears that EFF consumption remains a "personal" issue, and until the technology or marketing campaigns send consistent messages that everybody's actions count, then there remains a reluctance amongst consumers to change their actions. Further research is required to better understand why environmental consumption is not be a suitable topic for comparative social media sites in general. It is also important to better understand what type of messages would effect consumer change. Is the use of technology appropriate to effect large scale environmental change if consumers are unwilling to share, or compare their activities with others? 


\section{References}

I. Ajzen, The theory of planned behaviour, Organizational Behavior and Human Decision Processes, 50(2) (1991) 179-211.

J. Aertsens, W. Verbeke, K. Mondelaers, G. Van Huylenbroeck, Personal determinants of organic food consumption: a review, British Food Journal, 111(10) (2009) 1140-1167.

S. Albert, Temporal comparison theory, Psychological Review, 84(6) (1977) 485-503.

H. Allcott, Social norms and energy conservation, Journal of Public Economics, 95(9) (2011) 1082-1095.

L.G. Aspinwall, S.E. Taylor, Effects of social comparison direction, threat, and self-esteem on affect, self-evaluation, and expected success, Journal of Personality and Social Psychology, 64(5) (1993) 708-722.

L.J. Becker, Joint effect of feedback and goal setting on performance: A field study of residential energy conservation, Journal of Applied Psychology, 63(4) (1978) 428-433.

R. Bekkers, Measuring altruistic behavior in surveys: The all-or-nothing dictator game, in: Survey Research Methods, 1(3) 139-144), University of Groningen, 1977.

R.W. Belk, Three scales to measure constructs related to materialism: Reliability, validity, and relationships to measures of happiness, Advances in Consumer Research, 11(1) (1984) 291-297.

J. Blascovich, J. Tomaka. Measures of self-esteem, Measures of Personality and Social Psychological Attitudes, 1 (1991) 115-160.

M. Bleda, M. Valente, Graded eco-labels: A demand-oriented approach to reduce pollution, Technological Forecasting \& Social Change, 76 (2009) 512-524.

B.A. Browne, D.A. Kaldenberg, Conceptualizing self-monitoring: links to materialism and product involvement, Journal of Consumer Marketing, 14(1) (1997) 31-44.

S. Bonini, J. Oppenheim, Cultivating the green consumer, Stanford Social Innovation Review, 6(4) (2008) 56-61. 
B. Butler, Membership size, communication activity, and sustainability: A resource-based model of online social structures, Information Systems Research, 12 (4 )(2001) 346-362.

B.P. Buunk, R.L. Collins, S.E. Taylor, N.W. VanYperen, G.A. Dakof, The affective consequences of social comparison: either direction has its ups and downs, Journal of Personality and Social Psychology, 59(6) (1990) 1238-1249.

B.P. Buunk, T. Mussweiler, T., New directions in social comparison research, European Journal of Social Psychology, 31(5) (2001) 467-475.

B.P. Buunk, F.X. Gibbons, Social comparison: The end of a theory and the emergence of a field, Organizational Behavior and Human Decision Processes, 102(1) (2007) 3-21.

L. A. Cavanaugh, ., Because I (don't) deserve it: How relationship reminders and deservingness influence consumer indulgence, Journal of Marketing Research, 51(2), (2014), 218-232.

I. Cheah, I. Phau, Attitudes towards environmentally friendly products: The influence of ecoliteracy, interpersonal influence and value orientation, Marketing Intelligence \& Planning, 29(5) (2011) 452-472.

M.F. Chen, Consumer attitudes and purchase intentions in relation to organic foods in Taiwan: Moderating effects of food-related personality traits, Food Quality and Preference, 18(7) (2007), 1008-1021.

G.M. Chryssohoidis, A. Krystallis, Organic consumers' personal values research: Testing and validating the list of values (LOV) scale and implementing a value-based segmentation task. Food Quality and Preference, 16(7) (2005) 585-599.

R.B. Cialdini, R.R. Reno, C.A. Kallgren, A focus theory of normative conduct: recycling the concept of norms to reduce littering in public places, Journal of Personality and Social Psychology, 58(6) (1990) 1015-1026.

M. Cleveland, M. Kalamas, M. Laroche, Shades of green: linking environmental locus of control and pro-environmental behaviors, Journal of Consumer Marketing, 22(4) (2005) 198212. 
M. Cleveland, M., Kalamas, M. Laroche, "It's not Easy Being Green”: Exploring Green Creeds, Green Deeds, and Internal Environmental Locus of Control, Psychology and Marketing, 29 (2012) 293-305.

C.M.L. Collins, M.A. Koning, Customers' values, beliefs on sustainable corporate performance, and buying behaviour, Psychology \& Marketing, 24(6) (2007) 555-577.

D.E. Conroy, C.H. Yang, J.P. Maher, Behavior change techniques in top-ranked mobile apps for physical activity, American Journal of Preventive Medicine, 46(6) (2014) 649-652.

S. Darby, The Effectiveness of Feedback on Energy Consumption: A review for DEFRA of the literature on metering, billing, and direct displays, Environmental Change Institute, University of Oxford, 2006.

M. Dean, M.M. Raats, R. Shepherd, Moral concerns and consumer choice of fresh and processed organic Foods, Journal of Applied Social Psychology, 38(8) (2008) 2088-2107.

R. De Young, , Encouraging environmentally appropriate behavior: The role of intrinsic motivation, Journal of Environmental Systems, (15), (1986) 281-292.

I. Diaz-Rainey, D. Tzavara, Financing the decarbonized energy system through green electricity tariffs: A diffusion model of an induced consumer environmental market, Technological Forecasting \& Social Change, 79 (2012) 1693-1704.

M.D. Dickerson, J.W. Gentry, Characteristics of adopters and non-adopters of home computers, Journal of Consumer Research, 10 (1983) 225-235.

R.E. Dunlap, The new environmental paradigm scale: From marginality to worldwide use, The Journal of Environmental Education, 40(1) (2008) 3-18.

R.E. Dunlap, K.D. Van Liere, A.G. Mertig, R.E. Jones, New trends in measuring environmental attitudes: Measuring endorsement of the new ecological paradigm: a revised NEP scale, Journal of Social Issues, 56(3) (2000) 425-442. 
A. Ebreo, J. Hershey, J. Vining, Reducing solid waste linking recycling to environmentally responsible consumerism, Environment and Behavior, 31(1) (1999) 107-135.

B.G. Englis, D.M. Phillips, Does Innovativeness Drive Environmentally Conscious Consumer Behavior? Psychology \& Marketing, 30(2) (2013) 160-172.

L. Festinger, A Theory of Social Comparison Processes, Human Relations, 7 (2) (1954) 117140 .

J. Froehlich, Promoting Energy Efficient Behaviors in the Home through Feedback: The Role of Human-Computer Interaction, In Proceedings of the HCIC Winter Workshop Boaster Paper (Fraser, CO, USA, February, 2009).

F.X. Gibbons, B.P. Buunk, Individual differences in social comparison: development of a scale of social comparison orientation, Journal of Personality and Social Psychology, 76(1) (1999) 129.

N.J. Goldstein, R.B. Cialdini, V.A. Griskevicius, Room with a viewpoint: Using Social Norms to Motivate Environmental Conservation in Hotels, Journal of Consumer Research, 35 (2008) 3 .

G. Grankvist, H. Lekedal M. Marmendal, Values and eco-and fair-trade labelled products, British Food Journal, 109(2) (2007) 169-181.

C. Grevet, J. Mankoff, Motivating sustainable behavior through social comparison on online social visualization, Human-Computer Interaction International Conference, 2009.

M. Hauser, F.W. Nussbeck, K. Jonas, The Impact of Food-Related Values on Food Purchase Behavior and the Mediating Role of Attitudes: A Swiss Study, Psychology \& Marketing, 30(9) (2013) 765-778.

A.F. Hayes, Introduction to mediation, moderation, and conditional process analysis: A regression-based approach, Guilford Press, New York 2008. 
T.A. Heberlein, J.S. Black, Cognitive consistency and environmental action, Environment and Behavior, 13(6) (1981) 717-734.

P.M.Homer, L.R. Kahle, A structural equation test of the value-attitude-behavior hierarchy, Journal of Personality and Social Psychology, 54(4) (1988) 638.

T. Holmes, Eco-visualization: Combining Art and Technology to Reduce Energy Consumption, in: Proceedings of the C\&C (Washington, DC, USA, 13-15 June), ACM Press, 2007.

R.S. Hughner, P. McDonagh, A. Prothero, C.J. Shultz, J. Stanton, Who are organic food consumers? A compilation and review of why people purchase organic food, Journal of Consumer Behaviour, 6(2-3) (2007) 94-110.

IPCC: International Panel onClimate Change 2014. Fifth Assessment Report (2014). Available from [http://www.ipcc.ch/]. Accessed 23/11/2014.

K.J. Isaksen, S. Roper, The impact of branding on low-income adolescents: A vicious cycle? Psychology \& Marketing, 25(11) (2008), 1063-1087.

T. Jensen, Comparison process in energy conservation feedback effects, Advances in Consumer Research, 13 (1986) 486-491.

C. A., Kallgren, R. R Reno, \& R. B. Cialdini, A focus theory of normative conduct: When norms do and do not affect behavior, Personality and Social Psychology Bulletin, 26(8), (2000), 1002-1012.

W.E. Kilbourne M.C. LaForge, Materialism and its relationship to individual values. Psychology \& Marketing, 27(8) (2010), 780-798.

D. Langley, T. van den Broek, Exploring social media as a driver of sustainable behaviour: case analysis and policy implications, Internet Politics and Policy Conference, 2010. 
S. Lähteenoja, M. Lettenmeier, E. Kotakorpi, The ecological rucksack of households: huge differences, huge potential for reduction, Proceedings Conference of the Sustainable Consumption Research, 2008.

S. Lindenberg, L. Steg, Normative, gain and hedonic goal frames guiding environmental behaviour, Journal of Social Issues, 63(1) (2007), 117-137.

I. Lorenzoni, S. Nicholson-Cole, L. Whitmarsh, Barriers perceived to engaging with climate change among the UK public and their policy implications, Global Environmental Change, 17(3) (2007) 445-459.

R. Madrigal, L.R. Kahle, Predicting vacation activity preferences on the basis of valuesystem segmentation, Journal of Travel Research, 32(3) (1994) 22-28.

J. Mankoff, S.R. Fussell, T. Dillahunt, R. Glaves, C. Grevet, M. Johnson, D. Matthews, H.S. Matthews, R. McGuire, R. Thompson, A. Shick, L. Setlock, StepGreen.org: Increasing Energy Saving Behaviors via Social Networks. In Proceedings of the Fourth International AAAI Conference on Weblogs and Social Media, 2010 (Washington, DC, USA, 23-26 May).

T.L.Milfont, , C. G. Sibley, J. Duckitt, Testing the moderating role of the components of norm activation on the relationship between values and environmental behavior, Journal of Cross-Cultural Psychology, 41(1), (2010),124-131.

A. Nilsson, C. von Borgstede, A. Biel, Willingness to accept climate change strategies: The effect of values and norms, Journal of Environmental Psychology, 24(3) (2004) 267-277, http://dx.doi.org/10.1016

J.C. Nunnally, Psychometric Theory (2nd ed.). New York: McGraw-Hill, 1978.

I. Oakley, M. Chen, V. Nisi, Motivating sustainable behaviour, on ubiquitous Computing (2008) 174. 
M.C. Onwezen, G. Antonides, J. Bartels, The Norm Activation Model: An exploration of the functions of anticipated pride and guilt in pro-environmental behavior, Journal of Economic Psychology, 39, (2013), 141-153.

H.-J. Park, N.J. Rabolt, K.S. Jeon. Purchasing global luxury brands among young Korean consumers, Journal of Fashion Marketing and Management: An International Journal, 12.2 (2008) 244-259.

J. Paul, J. Rana, Consumer behavior and purchase intention for organic food, Journal of Consumer Marketing, 29(6) (2012) 412-422.

P. Petkov, F. Köbler, M. Foth, H. Krcmar, Motivating domestic energy conservation through comparative, community-based feedback in mobile and social media. In Proceedings of the 5th International Conference on Communities and Technologies (2011, June) (pp. 21-30). ACM.

S. Roberts, H. Humphries, V. Hyldon, Consumer Preferences for Improving Energy Consumption Feedback, Report to Ofgem, Centre for Sustainable Energy 2, no. 3 (2004): 19.

M. Rosenberg, L.I. Pearlin, Social class and self-esteem among children and adults, American Journal of Sociology, (1978) 53-77.

M. Rosenberg, C. Schooler, C. Schoenbach, F. Rosenberg, Global self-esteem and specific self-esteem: Different concepts, different outcomes, American Sociological Review, (1995) 141-156.

M. Rokeach, The nature of human values (438). New York: Free press, 1973.

W.P. Schultz, L. Zelezny, Values as predictors of environmental attitudes: Evidence for consistency across 14 countries, Journal of Environmental Psychology, 19(3) (1999) 255265. 
S.H. Schwartz, Normative Explanations of Helping Behavior: A Critique, Proposal and Empirical Test, Journal of Experimental Social Psychology, Science Direct 9 (4) (1973) 349364.

S.H. Schwartz, Normative Influences on Altruism, Advances in Experimental Social Psychology. 10 ( 1977) 221-279

S.H. Schwartz, Universals in the content and structure of values: Theoretical advances and empirical tests in 20 countries, Advances in Experimental Social Psychology, 25(1) (1992) 165.

E. Shafiei, H. Thorkelsson, E.I. Asgeirsson, B. Davidsdottir, M. Raberto, H. Stefansson, An agent-based modelling approach to predict the evolution of market share of electric vehicles: A case study from Iceland, Technological Forecasting \& Social Change, 79 (2012) 16831653.

J.V. Stanton, D.T. Guion, Consumer attitudes toward organic foods: An exploration of US market segments, Research in Consumer Behavior, 12 (2010) 5-41.

L. Steg, J. Groot, Explaining prosocial intentions: Testing causal relationships in the norm activation model, British Journal of Social Psychology, 49(4) (2010) 725-743.

P.C. Stern, T. Dietz. The value basis of environmental concern, Journal of Social Issues, 50(3) (1994) 65-84.

A. Stuart, N. Donaghue, Choosing to conform: The discursive complexities of choice in relation to feminine beauty practices. Feminism and Psychology, 22 (1) (2012) 98-121.

C. Tanner, S.W. Kast, Promoting sustainable consumption: determinants of green purchases by Swiss consumers, Psychology and Marketing, 20(10) (2003) 883-902.

A. Tarkiainen, S. Sundqvist, Subjective norms, attitudes and intentions of Finnish consumers in buying organic food, British Food Journal, 107(11) (2005) 808-822. 
A. Tarkiainen, S. Sundqvist, Product involvement in organic food consumption: Does ideology meet practice? Psychology and Marketing, 26(9) (2009) 844-863.

J. Thøgersen, Recycling and morality: A critical review of the literature, Environment and Behavior, 28(4) (1996) 536-558.

J. Thøgersen, Social marketing of alternative transportation modes, in: T. Garling, L. Steg (Eds.), Threats to the quality of urban life from car traffic: Problems, causes, and solutions (pp. 367-381), Amsterdam: Elsevier, 2007.

J. Thøgersen, A.K. Jørgensen, S. Sandager, Consumer decision making regarding a "green" everyday product, Psychology and Marketing, 29(4) (2012) 187-197.

D. Ubilava, K.A. Foster, J.L. Lusk, T. Nilsson, Effects of income and social awareness on consumer WTP for social product attributes, Technological Forecasting \& Social Change, 77 (2010) 587-593.

M. Vega-Zamora, F.J. Torres-Ruiz, E.M. Murgado-Armenteros, M. Parras-Rosa, Organic as a heuristic cue: What Spanish consumers mean by organic foods, Psychology and Marketing, 31 (2014) 349-359.

I. Vermeir, W. Verbeke, Sustainable food consumption: Exploring the consumer "attitudebehavioral intention" gap, Journal of Agricultural and Environmental Ethics, 19(2) (2006) 169-194.

B. Verplanken, R.W. Holland, Motivated decision making: Effects of activation and selfcentrality of values on choices and behaviour, Journal of Personality and Social Psychology, 82(3) (2012) 434.

J. Vining, A. Ebreo, What makes a recycler? A comparison of recyclers and nonrecyclers, Environment and Behavior, 22(1) (1990) 55-73. 
L. Wheeler, K. Miyake, Social comparison in everyday life, Journal of Personality and Social Psychology, 62(5) (1992) 760.

P. Windrum, T. Ciarli, C. Birchenhall, Environmental impact, quality and price: Consumer trade-offs and the development of environmentally friendly technologies, Technological Forecasting \& Social Change, 76 (2009) 552-566.

S. Winer, Experimentation in the 21st century: The importance of external validity, Journal of the Academy of Marketing Science 273 (1999) 349-358. 
Table 1: Scales used for this study

\begin{tabular}{|l|l|l|l|l|}
\hline Scale & $\begin{array}{l}\text { No. } \\
\text { items }\end{array}$ & Range & Mean & $\begin{array}{l}\text { Cronbach } \\
\text { alpha }\end{array}$ \\
\hline Self-esteem (Rosenberg 1995) & 10 & $1.20-5.2$ & 2.83 & .88 \\
\hline $\begin{array}{l}\text { Materialism (whole scale, Kilbourne \& } \\
\text { LaForge 2010) }\end{array}$ & 9 & $2.11-5.00$ & 3.27 & .74 \\
\hline $\begin{array}{l}\text { Success (MVS scale, Kilbourne \& LaForge } \\
\text { 2010) }\end{array}$ & 3 & $1.0-5.0$ & 3.22 & .79 \\
\hline $\begin{array}{l}\text { Centrality (MVS scale, Kilbourne \& LaForge } \\
\text { 2010) }\end{array}$ & 3 & $2.3-5.0$ & 3.43 & .79 \\
\hline $\begin{array}{l}\text { Happiness (MVS scale, Kilbourne \& LaForge } \\
\text { 2010) }\end{array}$ & 3 & $1.33-5.33$ & 3.15 & .73 \\
\hline Social comparison (Gibbons \& Buunk, 1999) & 12 & $1.36-4.36$ & 2.92 & .87 \\
\hline $\begin{array}{l}\text { Perceived barriers (adapted from Tanner \& } \\
\text { Kast, 2003) }\end{array}$ & 4 & $1.0-5.0$ & 3.00 & .63 \\
\hline Nature Rules (Englis \& Philips, 2013) & 6 & $1.00-3.67$ & 2.43 & .72 \\
\hline Humans Rule (Englis \& Philips, 2013) & 6 & $2.17-5.83$ & 3.84 & .67 \\
\hline $\begin{array}{l}\text { Individual norms towards EFF (Tanner \& } \\
\text { Kast, 2003) }\end{array}$ & 5 & $1.4-4.00$ & 3.03 & .74 \\
\hline $\begin{array}{l}\text { Social norms: attitude towards EFF (Tanner \& } \\
\text { Kast, 2003) }\end{array}$ & 3 & $1-4.00$ & 3.00 & .59 \\
\hline
\end{tabular}


Table 2. Relationships with Attitudes towards EFF

\begin{tabular}{|l|l|l|}
\hline Dependent variable: & $\begin{array}{l}\text { Individual norms: How I } \\
\text { should act towards EFF. }\end{array}$ & $\begin{array}{l}\text { Social norms: How others } \\
\text { should act towards EFF }\end{array}$ \\
\hline Social comparison & $.09^{\text {n.s. }}$ & $.248^{* *}$ \\
\hline Materialism & $-.23^{* *}$ & $-.18^{\text {n.s }}$. \\
\hline Self-esteem & $-.01^{\text {n.s. }}$ & $-.07^{\text {n.s }}$. \\
\hline Nature Rules & $.346^{* * *}$ & $.26^{* *}$ \\
\hline Humans Rule & $.03^{\text {n.s. }}$ & $-.07^{\text {n.s. }}$ \\
\hline \multicolumn{2}{|c|}{} \\
\hline $\mathrm{F}$ & $4.08^{* * *}$ & $4.80^{* * *}$ \\
\hline $\mathrm{R}^{2}$, adjusted $\mathrm{R}^{2}$ & .173 & .194 \\
\hline$* \mathrm{p} \leq 0.10 * 3^{*} \leq 0.05$ & $* * * \mathrm{p} \leq 0.01$ & 153 \\
\hline
\end{tabular}


Table 3: Moderated Relationships with Attitudes towards EFF

\begin{tabular}{|l|l|l|}
\hline Dependent & $\begin{array}{l}\text { Individual norms: How I } \\
\text { should act towards EFF. }\end{array}$ & $\begin{array}{l}\text { Social norms: How others } \\
\text { should act towards EFF }\end{array}$ \\
\hline Social comparison & $205^{*}$. & $.261^{*}$ \\
\hline Materialism & $-.261^{* *}$ & $-0.21^{*}$ \\
\hline Self-esteem & $.072^{\text {n.s. }}$ & $-0.04^{\text {n.s. }}$ \\
\hline Nature Rules & $0.35^{* * *}$ & $.239^{*}$ \\
\hline Humans Rule & $.06^{\text {n.s. }}$ & $-0.05^{\text {n.s. }}$ \\
\hline & \multicolumn{2}{|l|}{} \\
\hline Moderating Variables & \multicolumn{2}{|l|}{} \\
\hline $\begin{array}{l}\text { Social comparison/Self- } \\
\text { Esteem }\end{array}$ & $.037^{* * *}$ & $0.105^{\text {n.s. }}$ \\
\hline $\begin{array}{l}\text { Social } \\
\text { comparison/Materialism }\end{array}$ & $-0.24^{* *}$ & $-0.24^{* *}$ \\
\hline $\begin{array}{l}\text { Social } \\
\text { comparison/Naturerules }\end{array}$ & $-0.176^{\text {n.s. }}$ & $-0.02^{\text {n.s. }}$ \\
\hline $\begin{array}{l}\text { Social } \\
\text { comparison/HumansRule }\end{array}$ & $0-.13^{\text {n.s. }}$ & $-0.03^{\text {n.s. }}$ \\
\hline F & $4.74^{* * *}$ & $3.24^{* *}$ \\
\hline $\begin{array}{l}\mathrm{R}^{2}, \quad \text { adjusted R } \\
*^{2} \mathrm{p} \leq 0.10 * * \mathrm{p} \leq 0.05\end{array}$ & $.308^{* *} \mathrm{p} \leq 0.01$ & .233 \\
\hline
\end{tabular}


Table 4. Logistic Regression of Personal vs. Social comparison on Social Media

\begin{tabular}{|c|c|c|c|c|}
\hline \multicolumn{5}{|c|}{ Classification Table } \\
\hline & \multirow[t]{3}{*}{ Observed } & \multicolumn{3}{|c|}{ Predicted } \\
\hline & & & & $\%$ \\
\hline & & $\begin{array}{l}\text { Compare } \\
\text { with self }\end{array}$ & $\begin{array}{c}\text { Compare } \\
\text { with others }\end{array}$ & correct \\
\hline \multirow[t]{3}{*}{ Step 1} & \multirow{2}{*}{$\begin{array}{l}\text { Compare with self } \\
\text { Compare with others }\end{array}$} & 52 & 10 & 83.9 \\
\hline & & 21 & 20 & 48.8 \\
\hline & Overall percentage & & & 69.9 \\
\hline \multicolumn{5}{|c|}{ a. The cut value is .500} \\
\hline
\end{tabular}

\begin{tabular}{|l|l|l|l|}
\hline & $\begin{array}{l}\text { Regression } \\
\text { coefficients }\end{array}$ & Sig. & Exp (B) \\
\hline Self esteem & -0.099 & 0.757 & 0.905 \\
\hline Social comparison & -1.006 & 0.021 & 0.366 \\
\hline Materialism & -0.242 & 0.106 & 0.785 \\
\hline NatureRules & 0.838 & 0.057 & 2.311 \\
\hline HumansRule & -0.009 & 0.980 & 0.991 \\
\hline & & & \\
\hline Constant & -.505 & .023 & 0.604 \\
\hline Nagelkerke R square & 0.195 & & \\
\hline Cox and Snell R square & 0.144 & & \\
\hline
\end{tabular}




\section{Appendix 1 Scales}

\begin{tabular}{|c|c|}
\hline Scale & \\
\hline $\begin{array}{l}\text { Social } \\
\text { comparison }\end{array}$ & $\begin{array}{l}\text { I often compare how my loved ones (boyfriend / girlfriend / family members) are doing with } \\
\text { how others are doing } \\
\text { I always pay a lot of attention to how I do things compared to how others do things } \\
\text { If I want to find out how well I have done something, I compare what I have done with how } \\
\text { others have done } \\
\text { I often compare how I am doing socially (social skills / popularity) with other people } \\
\text { I am not the type of person who compares myself with others (R) } \\
\text { I never consider my situation in life relative to that of other people (R) } \\
\text { I often compare myself with others with respect to what I have accomplished in life } \\
\text { I often like to talk with others about mutual opinions and experiences } \\
\text { I often try to find out what others think who face similar problems as I face } \\
\text { If I want to learn more about something, I try to find out what others think about it } \\
\text { I never consider my situation in life relative to that of other people. }\end{array}$ \\
\hline Self-esteem & $\begin{array}{l}\text { I feel I do not have much to be proud of (R) } \\
\text { I take a positive attitude toward myself } \\
\text { On the whole, I am satisfied with myself } \\
\text { All in all, I am inclined to feel that I am a failure (R) } \\
\text { I feel I'm not a person of worth, at least on an equal plane with others } \\
\text { I certainly feel useless at times (R) } \\
\text { At times I think that I am no good at all (R) } \\
\text { I am able to do things as well as most other people } \\
\text { I feel I have a number of good qualities } \\
\text { I wish I could have more respect for myself (R) }\end{array}$ \\
\hline $\begin{array}{l}\text { Materialism } \\
\text { (Success) }\end{array}$ & $\begin{array}{l}\text { I admire people who own expensive homes, cars and clothes } \\
\text { Some of the most important achievements in life include acquiring possessions } \\
\text { Individual success is best measured by the material objects people own }\end{array}$ \\
\hline $\begin{array}{l}\text { Materialism } \\
\text { (Centrality) }\end{array}$ & $\begin{array}{l}\text { I try to keep my life simple as far as possessions are concerned } \\
\text { The things I own are really important to me } \\
\text { I usually buy only the things I need }\end{array}$ \\
\hline $\begin{array}{l}\text { Materialism } \\
\text { (Happiness) }\end{array}$ & $\begin{array}{l}\text { I have all the things I really need to enjoy life }(\mathrm{R}) \\
\text { I'd be happier if I could afford to buy more things } \\
\text { My life would be better if I owned certain things I don't have. }\end{array}$ \\
\hline $\begin{array}{l}\text { Contextual } \\
\text { Values: Nature } \\
\text { Rules }\end{array}$ & $\begin{array}{l}\text { The balance of nature is very delicate and easily upset } \\
\text { Despite our special abilities, humans are still subject to the laws of nature, } \\
\text { Plants and animals have as much right as humans to exist } \\
\text { When humans interfere with nature it often produces disastrous consequences } \\
\text { Humans are severely abusing the environment } \\
\text { If things continue on their present course we will soon experience a major ecological } \\
\text { catastrophe }\end{array}$ \\
\hline $\begin{array}{l}\text { Contextual } \\
\text { Values: Humans } \\
\text { Rule }\end{array}$ & $\begin{array}{l}\text { Human ingenuity will insure that we do not make the earth unlivable } \\
\text { Humans will eventually learn enough about how nature works to be able to control it } \\
\text { The balance of nature is strong enough to compete with the impacts of modern industrial } \\
\text { nations } \\
\text { Humans have the right to modify the natural environment to suit their needs } \\
\text { The so called "ecological" crisis facing humankind has been greatly exaggerated } \\
\text { Humans were meant to rule over the rest of nature }\end{array}$ \\
\hline $\begin{array}{l}\text { Contextual } \\
\text { Values: Growth } \\
\text { limits }\end{array}$ & $\begin{array}{l}\text { We are approaching the limit of the number of people the earth can support } \\
\text { The earth is like a spaceship with only limited room and resources } \\
\text { The earth has plenty of natural resources if we just learn how to develop them }\end{array}$ \\
\hline Social norms & $\begin{array}{l}\text { Everybody has a responsibility to contribute to environmental preservation by avoiding } \\
\text { packaged food products } \\
\text { Everybody should make a contribution to promoting environmentally friendly food production } \\
\text { by buying only these products } \\
\text { (Originally } 4 \text { items but } 2 \text { were not reliable). }\end{array}$ \\
\hline $\begin{array}{l}\text { Individual } \\
\text { Norms }\end{array}$ & $\begin{array}{l}\text { It is not important to me whether the products I buy are environmentally friendly (R) } \\
\text { Environmental protection is important to me when making purchases } \\
\text { If I can choose between environmentally friendly and conventional foods products I prefer } \\
\text { environmentally friendly }\end{array}$ \\
\hline
\end{tabular}




\section{Appendix 2: Correlations}

\begin{tabular}{|l|c|c|c|c|c|c|}
\hline & Self-Esteem & Materialism & $\begin{array}{l}\text { Social } \\
\text { comparison }\end{array}$ & NatureRules & HumansRule & $\begin{array}{l}\text { EFF Social } \\
\text { norms }\end{array}$ \\
\hline Self-Esteem & 1 & -0.097 & -0.166 & & 0.1 & \\
\hline Materialism & -0.097 & 1 & $0.357^{* *}$ & & & \\
\hline Social comparison & -0.166 & $0.357^{* *}$ & 1 & & & \\
\hline Nature Rules & -0.057 & 0.01 & $0.226^{*}$ & & & \\
\hline Humans Rule & 0.1 & 0.175 & 0.012 & $-0.384^{* *}$ & & \\
\hline EFF Individual norms & -0.025 & -0.19 & 0.087 & $0.352^{* *}$ & -0.14 & \\
\hline EFF social norms/ & -0.12 & -0.094 & $.254^{* *}$ & $0.347^{* *}$ & $-0.205^{*}$ & $0.423^{* *}$ \\
\hline
\end{tabular}


Figure 1: Norm Activation Model

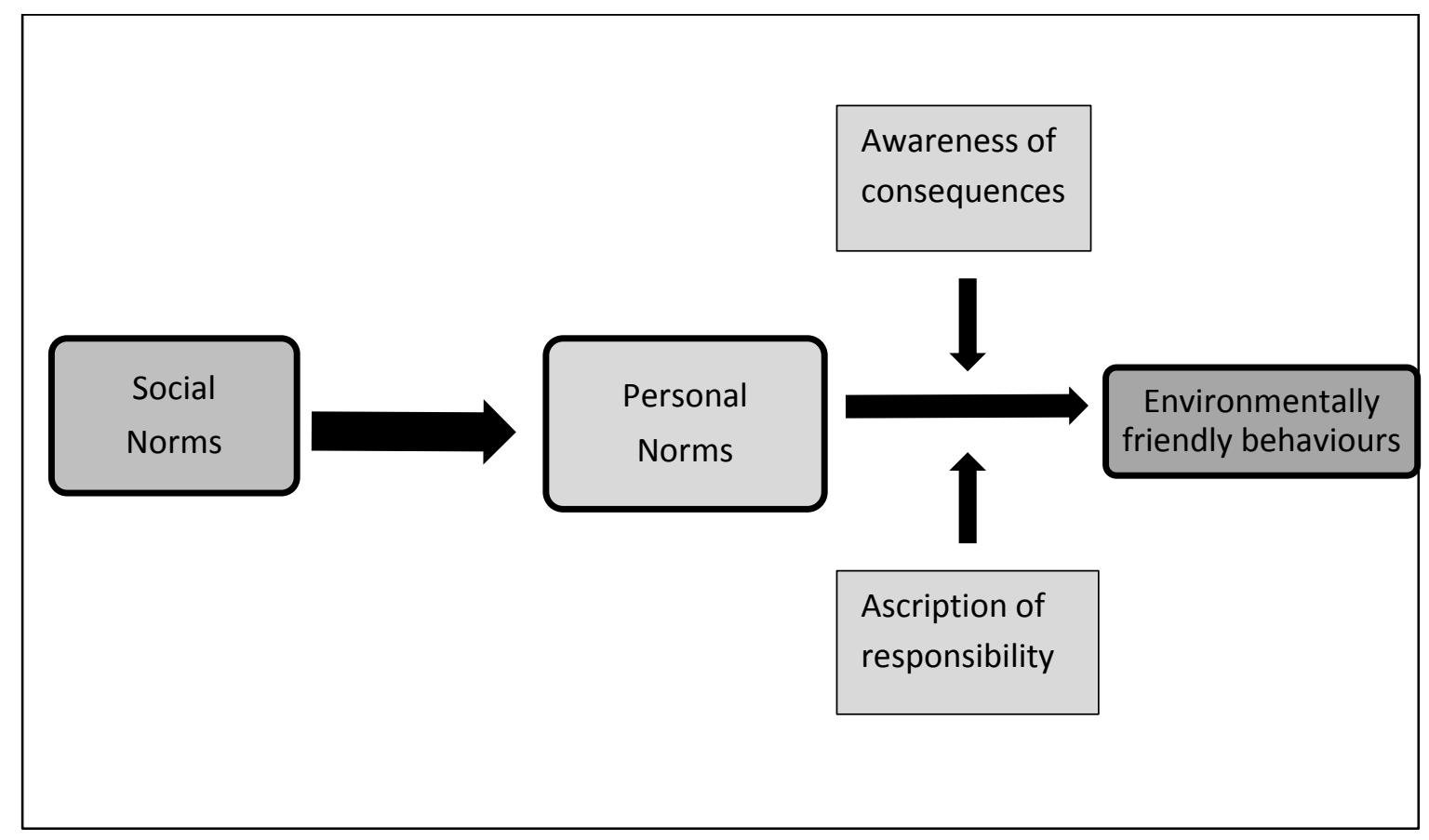

Source: Adapted from Schwartz (1977) 
Figure 2 Mock Facebook Page

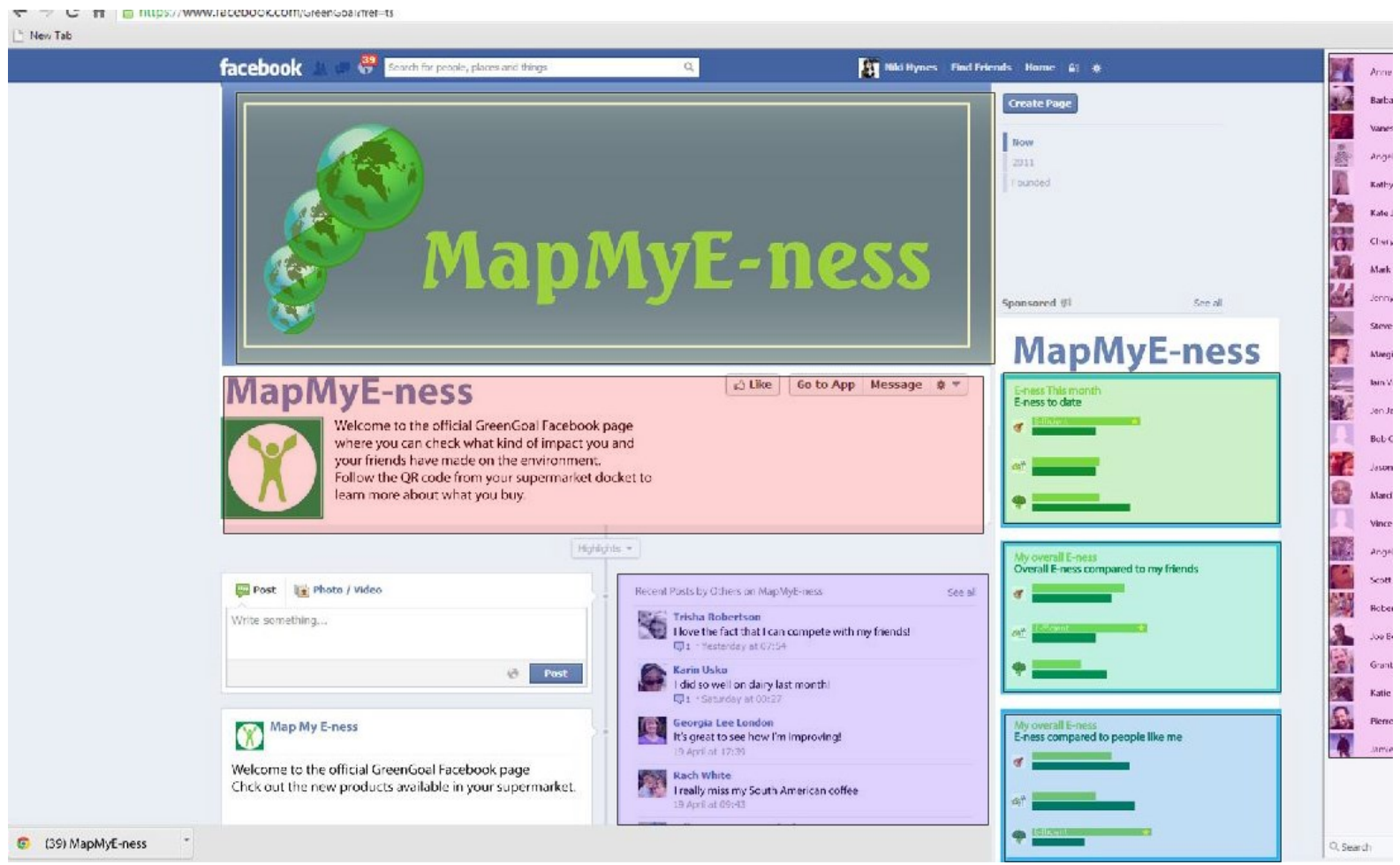


Figure 3. Comparative Behavioural Graphs on Facebook

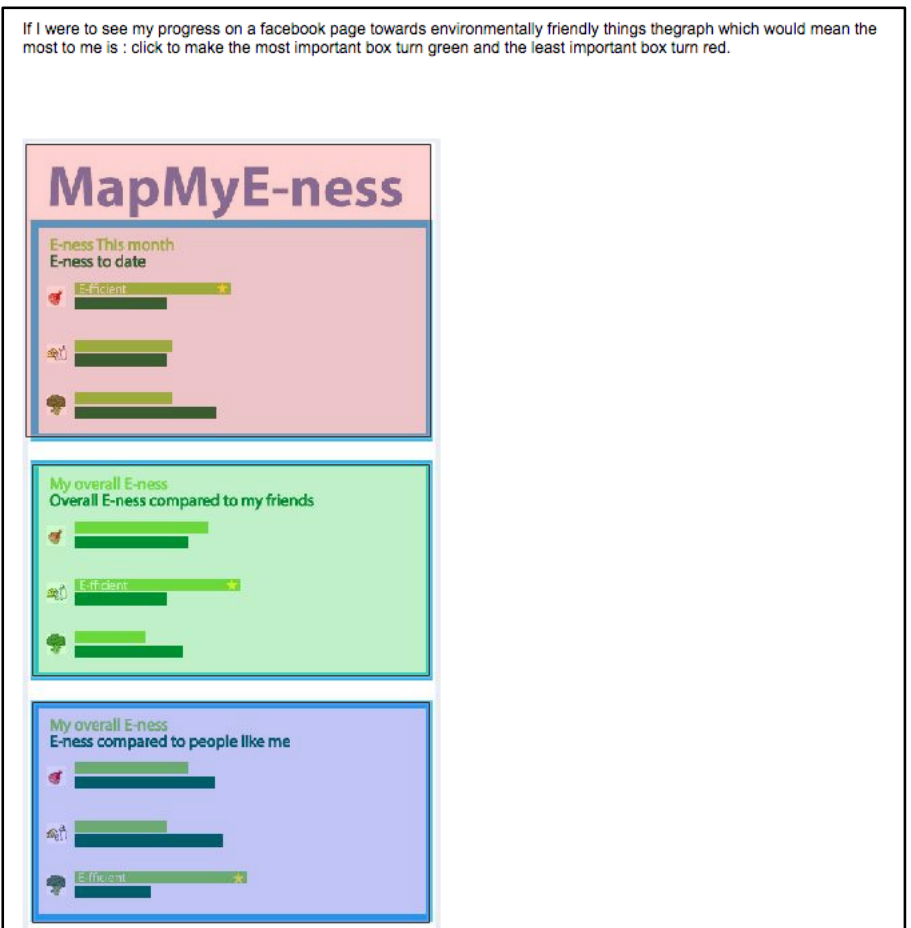

